\title{
Axillary Nerve
}

National Cancer Institute

\section{Source}

National Cancer Institute. Axillary Nerve. NCI Thesaurus. Code C52817.

A nerve originated from the posterior cord of the brachial plexus within the axilla then passing through the quadrangular space to innervate the deltoid and teres minor muscles and terminating as the superior lateral brachial cutaneous nerve. 